\title{
Population-based 10-year event-free survival after radical prostatectomy for patients with prostate cancer in British Columbia
}

\author{
Michael Peacock, MD; Jill Quirt, MD; W. James Morris, MD; Alan So, MD, FRCSC; Charmaine Kim Sing, MD; \\ Tom Pickles, MD, FRCPC; Scott Tyldesley, MD, FRCPC
}

Department of Radiation Oncology, Vancouver Cancer Centre, BC Cancer Agency, Vancouver, BC

Cite as: Can Urol Assoc J 2015;9(11-12):409-13. http://dx.doi.org/10.5489/cuaj.3288 Published online December 14, 2015.

\section{Abstract}

Introduction: We determined (1) the 10-year survival outcomes after radical treatment of prostate cancer and (2) the 10-year eventfree survival following radical prostatectomy (RP) at a populationlevel in British Columbia (BC), Canada.

Methods: We identified all men with a new diagnosis of prostate cancer in BC between 1999 and 2000. Those treated with RP, external beam radiotherapy (EBRT) or brachytherapy (BT) were identified. Overall survival, and prostate cancer specific survival (PCSS) were calculated from diagnosis using the Kaplan-Meier method. For those men treated with RP, we calculated the 10-year event-free survival (freedom from salvage EBRT or androgen ablation, or death from prostate cancer). Reasons for initiating androgen therapy were unknown and may include symptomatic metastatic disease or asymptomatic biochemical recurrence. An important limitation was the absence of prostate-specific antigen data for staging or follow-up.

Results: Among 6028 incident cases, RP was the curative-intent treatment within 1 year in 1360 (22.6\%) patients, EBRT in 1367 $(22.7 \%)$, and BT in 357 (5.9\%). The 10-year PCSS was 98\% for RP, 95\% for EBRT and 98\% for BT (log rank $p<0.0001)$. The 10 -year overall survival was $87 \%$. The 10 -year event-free survival for those treated with RP was $79 \%$ and varied with Gleason grade: $87 \%, 74 \%$, and $52 \%$ for Gleason $2-6,7$, and $8-10$, respectively $(p<0.0001)$.

Conclusions: This population-based study provides outcomes which can inform patient decision-making and provide a benchmark to which other therapies can be compared. Event-free rates for patients treated with RP vary with Gleason score. There is room for improvement in the outcomes of patients with high Gleason score treated with RP.

\section{Introduction}

With prostate-specific antigen (PSA) screening and early detection, many men are diagnosed with early localized prostate cancer, ${ }^{1}$ and there is considerable controversy regarding optimal management. Randomized trials have compared a watchful waiting approach with radical prostatectomy (RP) in men with early prostate cancer. ${ }^{2,3}$ One trial is the Prostate Cancer Intervention versus Observation Trial (PIVOT), which showed a non-significant difference in overall survival with a median follow-up of 10-years in those undergoing observation or prostatectomy (47.0 vs. $49.9 \%$ ); PIVOT was done in the early PSA screening era. ${ }^{3}$ These results are in contrast to those found by the Scandinavian Prostate Cancer Group Study Number 4 (SPCG-4) done in the pre-PSA screening era. SPCG-4 showed a significant improvement in prostate cancer specific mortality (14.6 vs. $20.7 \%)$, as well as allcause mortality ( 46.1 vs. $52.7 \%$ ) at 15 years in favour of RP in men under 65 years old. ${ }^{2}$

These studies provide benchmarks for RP outcomes, however, there is little published population-based data on the outcomes for patients with prostate cancer treated with RP. Furthermore, while overall survival remains an important endpoint, there is little data regarding freedom from salvage treatment following RP, which can have a significant affect quality of life.

The first objective of our study was to determine the longterm overall survival and prostate cancer specific survival (PCSS) of patients undergoing RP, EBRT and BT at a population level. The second objective was to retrospectively determine the clinically significant prostate-related eventfree survival of patients undergoing RP at a population level in British Columbia (BC). We defined an "event" as the first of either death from prostate cancer, use of salvage radiotherapy more than 6 months after RP or initiation of androgen deprivation therapy more than 24 months after RP. 
Peacock et al.

\section{Methods}

In BC, with an estimated population of 4.6 million people, the BC Cancer Registry (BCCR) contains all anatomical and cytological pathology reports with a diagnosis of malignancy. All cause and date of death data from death certificates and autopsy are incorporated in the BCCR. Pathologic stage, Gleason score and type of surgical therapy were abstracted from these records for incident cases diagnosed between January 1999 and December 2000. All cases treated with $\mathrm{RP}$ were identified based on pathology reports in the BCCR describing a RP.

The BC Cancer Agency (BCCA) is responsible for all radiotherapy delivered in the province, and for dispensing of all antineoplastic drugs, including anti-androgen (hormonal) therapy, prescribed in BC. Patients referred to the BCCA have additional demographic, pathologic, staging and treatment information recorded prospectively into an electronic database, which includes variables on external beam radiotherapy (EBRT), brachytherapy (BT). All data on the use of EBRT, BT, and androgen ablation therapy were attained for incident cases diagnosed in 1999 and 2000.

For our first objective, PCSS and overall survival were calculated from the date of diagnosis to date of death, or last registry update at time of analysis for those treated with curative intent EBRT, BT or RP using the Kaplan-Meier method. Results were then stratified according to pathologic T-stage and Gleason grade. Since baseline PSA measurements are not collected centrally in BC, risk stratification data were not available. Treatment and risk factor groups were compared for prostate specific survival using log-rank tests. Follow-up PSA data, and clinical relapse data were not captured in the database. Therefore, biochemical endpoints cannot be used to reliably compare the efficacy of different treatment modalities. Therefore for the second objective, a surrogate endpoint for relapse, meant to exclude biochemical recurrences not requiring intervention, was used.

This surrogate relapse event was the first of initiation of salvage androgen ablation or salvage radiotherapy after RP, or death from prostate cancer. A 24-month cut-off in defining an event was chosen to accommodate the use of adjuvant androgen ablation therapy. We defined salvage radiotherapy as any radiation initiated more than 6 months after surgery to exclude any cases that would have been treated with adjuvant radiotherapy. The definition for an event was specific to RP and could not be applied to either EBRT or BT. All patients recorded as having died of prostate cancer without having received androgen ablation prior to death were reviewed, and a sensitivity analysis was performed to assess the impact of including such cases.

\section{Results}

In total, 6028 men were diagnosed with prostate cancer in BC between January 1, 1999 and December 31, 2000. Of these cases, RP was performed in $23 \%$ of patients, radical EBRT in another $23 \%$, and BT in $6 \%$. In the remaining $48 \%$ of patients, no radial treatment was initiated within a year of diagnosis.

The 10-year prostate cancer specific survival (PCSS) rates were $95 \%$ for those treated with EBRT and $98 \%$ for those treated BT or RP (log rank $p<0.0001)$ (Fig. 1). However, a greater proportion of men treated with EBRT would be expected to have higher risk disease compared to BT. However as preoperative stage and PSA were not available on all RP cases, further analysis with multivariable approach was not pursued.

With respect to our primary objective, $21 \%$ of patients at the 10-year follow-up had experienced an event (Fig. 2). The individual events included 210 patients (15\%) receiving salvage radiotherapy, 168 patients $(12.4 \%)$ receiving salvage androgen ablation, and 33 patients (2.4\%) dying of prostate cancer within 10 years of diagnosis. Five patients had cause of death registered as prostate cancer without having received anti-androgens prior to death. These cases were reviewed. Four of the 5 patients had other malignant diagnosis, which may have been the actual cause of death,

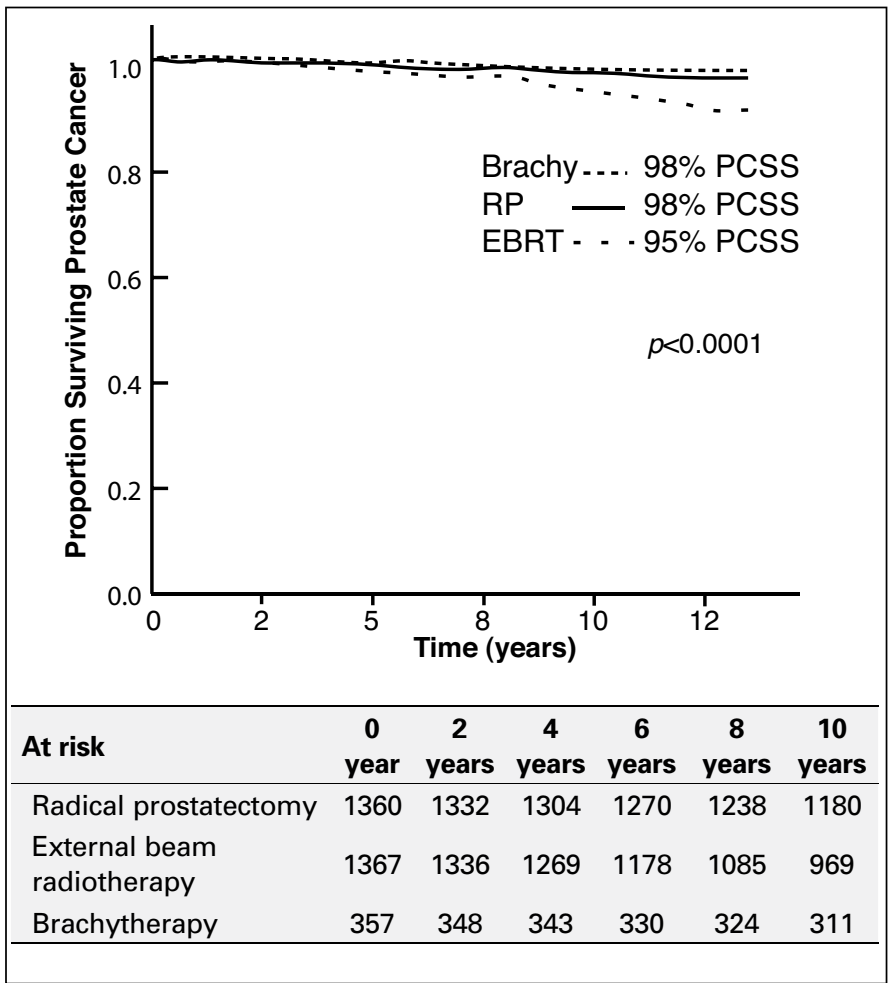

Fig. 1. 10-year prostate cancer specific survival for patients treated in British Columbia by modality. RP: radical prostatectomy; Brachy: brachytherapy; EBRT: external beam radiotherapy; $\mathrm{PCa}$ : prostate cancer. 


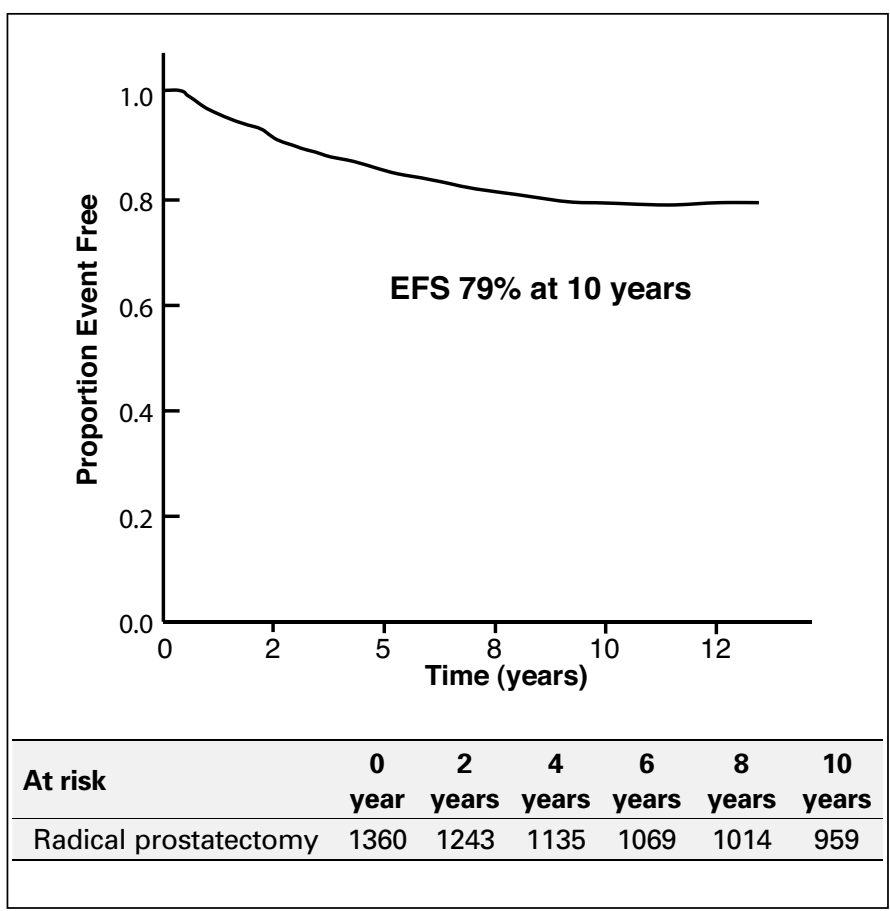

Fig. 2. 10-year Event free survival after radical prostatectomy in British Columbia for incident cases from 1999-2000. EFS: event-free survival.

and a patient was treated palliatively without re-referral prior to death. If these 5 cases are excluded from the analysis, the actuarial event rate decreased by $0.4 \%$ at 10 years. Thirtyfive patients had received pelvic irradiation within the first 6 months of RP, and of these, 25 had no other subsequent relapse. With these 25 cases included as events, the 10 -year event rate increased by $1.8 \%$. The Gleason score subgroup analysis at the 10-year event-free survival point, $87 \%$ were at Gleason score 2-6 and 52\% at Gleason score 8-10 (by Gleason score (Fig. 3) $(p<0.0001)$.

The median age of patients who underwent RP was 63 years, with most $(65 \%) \leq 65$ years old, and $\leq 93.2 \%$ were 70 years old at diagnosis. Most men who underwent prostatectomy $(52.8 \%)$ had a Gleason score $\leq 6$ on final pathology (or core biopsy if final pathology unavailable or treated with neoadjuvant hormone therapy. The vast majority of these RP patients (77\%) had pathological T2 stage (Table 1).

PCSS for all 1360 prostatectomy patients was $98 \%$ at 10 years, with an overall survival of $87 \%$ (Fig. 4). When stratified by Gleason score, Gleason 8-10 patients had a PCSS of $89 \%$ at 10 years. The results are compared to previously published results from large institutions, available population-based series and the previously mentioned randomized trials comparing RP to watchful waiting (Table 2). $\cdot^{2-9}$

\section{Discussion}

We found that $21 \%$ of all patients treated with prostatectomy in BC between 1999 and 2000 had a clinically meaningful

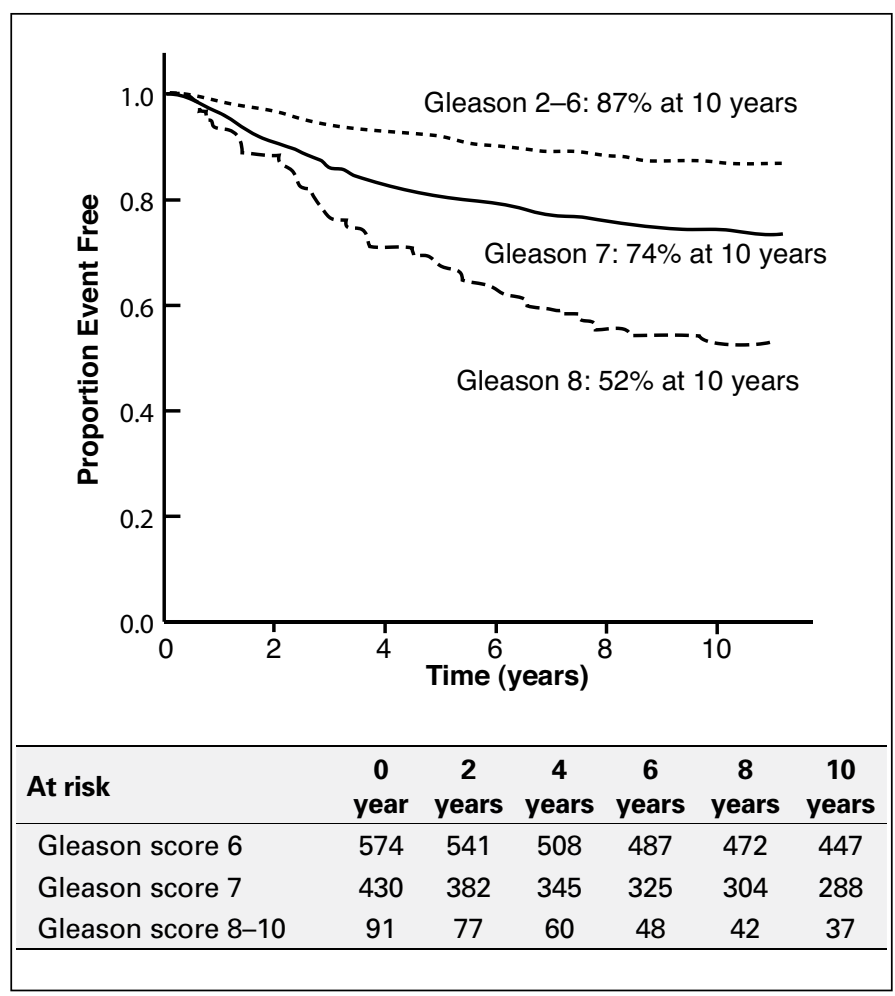

Fig. 3. 10-year event free survival for prostatectomy patients by Gleason score.

event with either death due to prostate cancer, treatment with salvage radiotherapy, or initiation of androgen withdrawal therapy 2 or more years after surgery. As expected, more patients with high-grade disease experienced an event. We also found that the 10-year PCSS and the overall survival after RP in our population was $97.6 \%$ and $87 \%$, respectively.

\begin{tabular}{|c|c|c|c|}
\hline & & $\mathbf{N}$ & $\%$ \\
\hline \multirow{5}{*}{ Age at diagnosis } & $<65$ & 883 & $65 \%$ \\
\hline & $65-70$ & 385 & $28 \%$ \\
\hline & $70-75$ & 78 & $6 \%$ \\
\hline & $>75$ & 14 & $1 \%$ \\
\hline & Median (IQR) & \multicolumn{2}{|c|}{63 years $(58-67)$} \\
\hline \multirow[t]{4}{*}{ Gleason score* } & $2-6$ & 718 & $52.8 \%$ \\
\hline & 7 & 510 & $37.5 \%$ \\
\hline & $8-10$ & 111 & $8.2 \%$ \\
\hline & Unknown & 21 & $1.5 \%$ \\
\hline \multirow{4}{*}{ pT Stage } & 2 & 1047 & $77 \%$ \\
\hline & 3 & 227 & $16.7 \%$ \\
\hline & 4 & 7 & $0.5 \%$ \\
\hline & Unknown & 79 & $5.8 \%$ \\
\hline
\end{tabular}


Peacock et al.

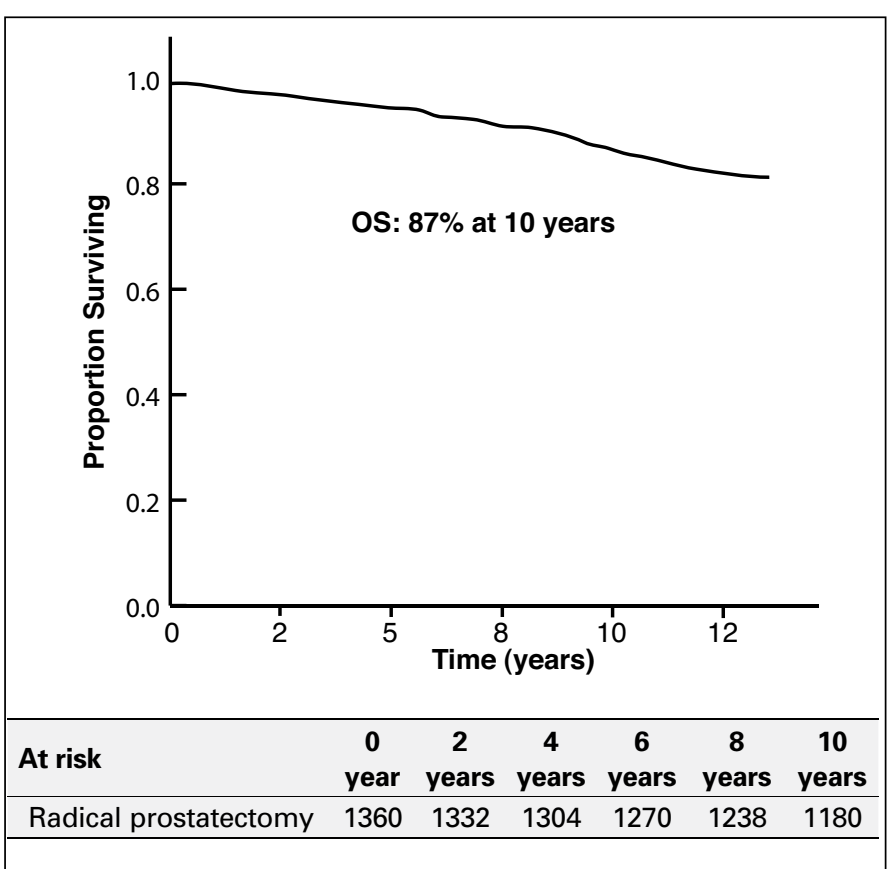

Fig. 4. 10-year overall survival for patients treated with prostatectomy in British Columbia. OS: overall survival.

These results, especially with the regards to overall survival, are significantly higher than those shown by previously conducted randomized studies comparing watchful waiting and prostatectomy, but appear consistent with other large institutional series and population studies. ${ }^{2-9}$
There are many men with Gleason 7 or higher prostate cancer in BC (47\%) compared to patients in the PIVOT $(26.3 \%)$ and SPCG-4 (31.5\%) trials. Despite this, the younger average age (63 years) may explain the higher overall survival and appears to indicate a greater selection of younger men by surgeons in $\mathrm{BC}$ during the study period. The selection of younger patients is supported by subset analysis in the SPCG-4 study demonstrating the mortality benefits of prostatectomy over watchful waiting in men under 65 years old. Only a small percentage of RP patients (6\%) were over 70 . Alternatively, Gleason and stage migration may account for the higher overall Gleason scores and improved outcomes. ${ }^{10}$

Other factors may have contributed to the favourable overall survival of our population. For example, average life expectancy for a male aged 65 years in $\mathrm{BC}$ was 17 years during this era, ${ }^{11}$ and $\mathrm{BC}$ surgeons likely select not only younger patients, but also those in good overall health.

In patients with Gleason 8-10 high-risk disease, the 10-year PCSS was $89 \%$. At a population level, these results are comparable to results previously published by Loeb and colleagues from their single-surgeon experience at John's Hopkins. ${ }^{12}$ In 175 men with D'Amico high-risk prostate cancer, the 10 -year PCSS was $92 \% .^{12}$ The event rate, however, in men with Gleason 8-10 disease in BC was proportionally higher, with only $52 \%$ event-free at 10 years. These results help inform patient counselling (especially in patients with high-risk disease); patients should be aware that they may still require multimodality treatment after surgery. In fact,

Table 2. Literature comparison of long-term prostatectomy outcomes

\begin{tabular}{|c|c|c|c|c|c|c|}
\hline & & $\begin{array}{l}\text { No. patients (RP/ } \\
\text { total study) }\end{array}$ & Risk category & Mean age & 10 -year OS (\%) & $\begin{array}{c}\text { 10-year PCSS } \\
\text { after RP (\%) }\end{array}$ \\
\hline \multicolumn{7}{|l|}{ Randomized trials } \\
\hline PIVOT & Wilt et al. ${ }^{3}$ & $364 / 731$ & $\begin{array}{l}21 \% \text { D'Amico high } \\
\text { risk }\end{array}$ & 67 & $64 *$ & $96^{*}$ \\
\hline SPCG-4 & Bill-Axelson et al. ${ }^{2}$ & $347 / 695$ & $\begin{array}{c}37.8 \% \text { low risk (PSA } \\
<10, \text { Gleason }<7 \\
\text { WHO grade } 1 \text { ) }\end{array}$ & 65 & $73 *$ & $90^{*}$ \\
\hline \multicolumn{7}{|l|}{ Institutions } \\
\hline $\begin{array}{l}\text { MSKCC/Baylor/U of } \\
\text { M/Cleveland }\end{array}$ & Eggener et al. ${ }^{4}$ & 11521 & GS 8-10: $6 \%$ & 60 & $83 *(15$ years $67 \%)$ & $\begin{array}{c}95^{*} \text { (15 years } \\
93 \%)\end{array}$ \\
\hline BJH/Cleveland & Kibel et al. ${ }^{5}$ & 6485 & $\begin{array}{c}\text { GS 8-10: 4\%, } \\
\text { D'Amico high risk } \\
8 \%\end{array}$ & $60 / 61$ & 89 & 98 \\
\hline \multicolumn{7}{|l|}{ Population series } \\
\hline Austria & Wehrberger et al. ${ }^{6}$ & 33580 & NR & NR & $\begin{array}{c}87 * \text { (patients age } \\
50-59)\end{array}$ & $98^{*}$ \\
\hline SEER & Lu-Yao et al. ${ }^{7}$ & 23274 & Grade 3: $22 \%$ & 65.8 & $\begin{array}{l}\text { G1: } 77 \\
\text { G2: } 71 \\
\text { G3: } 54\end{array}$ & $\begin{array}{l}\text { G1: } 94 \\
\text { G2: } 87 \\
\text { G3: } 67\end{array}$ \\
\hline CaPSURE & Cooperberg et al. ${ }^{8}$ & 5066 & GS 8-10 5.7\% & 62 & NR & $95^{*}$ \\
\hline Quebec & Jeldres et al. ${ }^{9}$ & 4997 & NR & 65 & 75 & NR \\
\hline British Columbia & Current study & 1360 & GS 8-10: $6.5 \%$ & 63 & 87 & 98 \\
\hline
\end{tabular}


these results may underestimate those receiving additional treatment, which may have included adjuvant hormonal therapy within 2 years and/or radiotherapy within 6 months (e.g., adjuvant radiotherapy).

A larger series of patients from the Surveillance, Epidemiology, and End Results (SEER) database treated with either RP or radiation were compared with long-term results for prostate cancer specific mortality (PCSM).$^{13}$ In the lowrisk group, 10 -year PCSM was 1.4 versus $3.9 \%$, in favour of RP. ${ }^{13}$ Details on radiotherapy technique, including BT as well as dose and fractionation, were not included but seem congruent with our results showing improved PCSS with RP over EBRT; ${ }^{13}$ however, in both circumstances, EBRT patients are likely older, less fit to undergo RP, or have higher risk disease, making direct comparison difficult. It is also hard to generalize the historic EBRT outcomes, as patients were treated before dose-escalated RT, which improves biochemical control rates. ${ }^{14-16}$ In addition, the results of BT in our study match those of RP in terms of PCSS.

The limitations of our study include missing pathology reports ( $1.5 \%$ missing Gleason grade). Our series also included 58 patients that had a RP as part of a cystoprostatectomy for concurrent bladder cancer and often the prostate cancer was found incidentally. Although such patients were registered with prostate cancer, surgical management was directed to treat their bladder cancer. We were not able to review all relevant hospital information to verify cause of death, which could have been under-reported and biased our results to a lower event rate. Pathology did not always undergo central review to confirm Gleason grading from outside hospitals. We were not able to capture reasons for initiating androgen therapy, such as symptomatic metastatic disease or asymptomatic biochemical recurrence. Also, we did not have PSA data for staging or follow-up. Nevertheless, we defined our primary outcome based on clinically significant events that have meaning to patients in the context of comprehensively available death, radiotherapy and pharmaceutical data.

\section{Conclusion}

The described long-term results of treatment of prostate cancer by prostatectomy in BC show a higher overall survival than the PIVOT and SPCG-4 randomized studies, but comparable with other population-based and large institutional series. Ten-year prostate cancer specific mortality rates are low across all radical treatment modalities in BC. However, many patients with high-grade disease will require additional multimodality treatment and this should be discussed with the patient prior to RP.

Acknowledgements: Presented at the Canadian Association of Radiation Oncology (CARO) Annual Scientific Meeting Sept 2012. Ottawa, ON. Funded in part by a grant from Canadian Association of Radiation Oncology ACURA grant.
Competing interests: Dr. Peacock, Dr. Quirt, Dr. Morris, Dr. Sing and Dr. Pickles declare no competing financial or personal interests. Dr. So is a member of the advisory boards for Amgen, Janssen, and Astellas. He has a patient for a product by CDRD. He is currently participating in clinical trials with Amgen, Cougar, Janssen, and Astellas. Dr. Tyldesley has received honoraria and speaking fees from Sanofi, Amgen, Janssen, Ferring, Bayer, and AstraZeneca.

This paper has been peer-reviewed.

\section{References}

1. Canadian Cancer Society's Steering Committee on Cancer Statistics. Canadian Cancer Statistics 2012. Toronto, ON: Canadian Cancer Society; 2012.

2. Bill-Axelson A, Holmberg L, Ruutu M, et al. Radical prostatectomy versus watchful waiting in early prostate cancer. N Engl J Med 2011;364:1708-17. http://dx.doi.org/10.1056/NEJMoa1011967

3. Wilt TJ, Brawer MK, Jones KM, et al. Radical prostatectomy versus observation for localized prostate cancer. N Engl J Med 2012;367:203-13. http://dx.doi.org/10.1056/NEJMoal113162

4. Eggener SE, Scardino PT, Walsh PC, et al. Predicting 15-year prostate cancer specific mortality after radical prostatectomy. J Urol 201 1;185:869-75. http://dx.doi.org/10.1016/i.juro.2010.10.057

5. Kibel AS, Ciezki JP, Klein EA, et al. Survival among men with clinically localized prostate cancer treated with radical prostatectomy or radiation therapy in the prostate specific antigen era. J Urol 2012;187:1259-65. http://dx.doi.org/10.1016/i.juro.2011.11.084

6. Wehrberger C, Berger I, Willinger M, et al. Radical prostatectomy in Austria from 1992 to 2009: An updated nationwide analysis of 33,580 cases. J Urol 2012;187:1626-31. http://dx.doi.org/10.1016/i. juro.2011.12.080

7. Lu-Yao GL, Yao SL. Population-based study of long-term survival in patients with clinically localised prostate cancer. Lancet 1997;349:906-10. http://dx.doi.org/10.1016/S0140-6736(96)09380-4

8. Cooperberg MR, Vickers AJ, Broering JM, et al. Comparative risk-adjusted mortality outcomes after primary surgery, radiotherapy, or androgen-deprivation therapy for localized prostate cancer. Cancer 2010;116:5226-34. http://dx.doi.org/10.1002/cncr.25456

9. Jeldres C, Suardi N, Perrotte P, et al. Survival after radical prostatectomy and radiotherapy for prostate cancer: A population-based study. Can Urol Assoc J 2009;3:13-21.

10. Albertsen PC, Hanley, JA, Barrows GH, et al. Prostate cancer and the Will Rogers phenomenon. J Natl Cancer Inst 2005;97:1248-53. http://dx.doi.org/10.1093/inci/dij248

11. Ministry of Labour, Citizens' Services and Open Government. 1950-2011: BC Stats. British Columbia: BC Vital Statistics; Feb 2012.

12. Loeb S, Schaeffer EM, Trock BJ, et al. What are the outcomes of radical prostatectomy for high-risk prostate cancer? Urology 2010;76:710-4. http://dx.doi.org/10.1016/i.urology.2009.09.014

13. Abdollah F, Schmitges J, Sun $M$, et al. Comparison of mortality outcomes after radical prostatectomy versus radiotherapy in patients with localized prostate cancer: A population-based analysis. Int I Urol 2012;19:836-44. http://dx.doi.org/10.1111/i.1442-2042.2012.03052.x

14. Al-Mamgani A, van Putten WL, Heemsbergen WD, et al. Update of Dutch multicenter dose-escalation trial of radiotherapy for localized prostate cancer. Int J Radiat Oncol Biol Phys 2008;72:980-8. http:// dx.doi.org/10.1016/i.i.irobp.2008.02.073

15. Kuban DA, Tucker SL, Dong L, et al. Long-term results of the MD Anderson randomized dose-escalation trial for prostate cancer. Int J Radiat Oncol Biol Phys 2008;70:67-74. http://dx.doi.org/10.1016/i. iirobp.2007.06.054

16. Zelefsky MJ, Yamada Y, Fuks Z, et al. Long-term results of conformal radiotherapy for prostate cancer: Impact of dose escalation on biochemical tumor control and distant metastases-free survival outcomes. Int J Radiat Oncol Biol Phys 2008;71:1028-33. http://dx.doi.org/10.1016/i.i.irobp.2007.11.066

Correspondence: Dr. Scott Tyldesley, BC Cancer Centre, 600 W 10th Ave, Vancouver, BC V5Z 4E6; styldes@bbccancer.bc.ca 